\title{
Government Support and Infrastructure: \\ Realizing the value of collaborative work
}

\author{
Peter LeVesque
}

$\mathrm{T}$

his article is a discussion of some of the roles of government in the support of community-campus research, otherwise called community-based research, citizen science, community-university research alliances or collaborative research. It is not a comprehensive analysis but may lead some readers to further investigate how government may best support collaborative research for collective benefit. I am writing from the perspective of a former staff member of a Canadian Federal funding agency who also has experience working with provincially funded institutions involved in community-based research. An introduction to programs such as CURA (Canada) and PICRI (Ile-de-France) and a Centre of Excellence for Child and Youth Mental Health (Ontario) is presented. I argue that the success of such programs is an indicator that government support of communitycampus partnerships and science and society interactions produces

Gateways: International Journal of Community Research and Engagement No 1 (2008): 150-164

(c) UTSePress and the author 
significant social and economic value that is currently left unrealized by traditional research modalities. As such, greater support in the form of incentives and infrastructure are called for. A taxonomy applied to the role of the State in supporting public health initiatives is suggested as a framework from which to build specific recommendations for further government investments.

\section{Growing OR Producing KNOWLEDGe?}

Michael Gibbons et al. (1994) described the new methods for the production of knowledge. Although they recognized that their Mode One and Mode Two categories were insufficient descriptors, what was clear to them was that our collective understanding of knowledge production is changing. Knowledge is not only a product but also a process and a participative one at that.

Mode One research is traditionally organized in universities. The main objective is the production of 'new' knowledge. The 'pure' disciplines are the location of knowledge production and scientific recognition. There is a staging of processes from fundamental to applied research. The peer review system is the predominant form of assessment both for the research processes and the products generated from these processes, as well as the careers of the people involved. The main targets for diffusion of this new knowledge are peer-reviewed journals. This form of knowledge production is generally well supported with incentives - rank, tenure, and promotion - as well as infrastructure such as institutions, associations, conferences and an apparatus for sharing and communicating results.

In their analysis, Gibbons et al. identified a new mode of knowledge production - Mode Two. This knowledge is produced in the context of application, in problem solving, and in the spaces formed by relationships. The locus of production tends to be transdisciplinary as well as transectoral. There is heterogeneity of people involved as well as organizational diversity. There is a greater level of social accountability and reflexivity. There is a form of quality control that goes beyond methodological or theoretical rigorousness, to one that includes cultural sensitivity and its applicability to real world problems, with real people in real places. Gibbons states that Mode Two is an indicator of the end of the academic monopoly on the assessment of research. Gibbons also states that this new mode of 
knowledge production implies a diversification and deinstitutionalization of knowledge diffusion activities.

Contrary to Mode One, current supports for Mode Two are poorly developed, sparsely distributed and the costs of sharing and communicating are often underwritten by the individuals involved. Yet, Mode Two is growing and attracting an increasing number of people. While this trend is somewhat paradoxical, what is clear from reading Gibbons is that research is evolving from a complicated process into a complex one. This is a process that is emergent and perhaps can be described as more organic.

\section{UNREALIZED VALUE FROM RESEARCH FINDINGS}

During the six-year period that I spent at the Social Sciences and Humanities Research Council of Canada (SSHRC), I had the opportunity to look at the results of several thousand funded research projects. While all of them were submitted to a peer review process and the results thereof disseminated via the traditional peer review channels, it was clear to me and other members of the Advisory Council and staff that the full potential value of this research was not being fully realized.

As a result of trying to determine why so much work was not producing its full value, I began to see research as three fundamental questions: what, so what and now what. The 'what' or content of basic research is found in the data, information, descriptions, and stories that are produced using a wide range of disciplinary tools and methods. The 'so what' is related to secondary analyses, to the creation of meaning, to myriad interpretations and to the contextualization of the data, information, descriptions and stories referred to above. 'Now what' relates to the application of content within context and to the capacity for action, decision-making, and decisions that produce added value.

'Now what' leads to the production of value, most traditionally in the form of product, programs and policies. However, there is significant value to be found in the changing of perspectives, such as that which led to the improvement in the lives of women in society or of our Aboriginal populations, and greater cultural tolerance. Further value is found in the creation of new procedures and processes, whether this is within business, government or the not-for-profit sector. There is further value still, in the improvement of professional practice and in the translation of research into new people skills. The 
processes that assist in the realization of the value of research findings are now commonly referred to as knowledge mobilization, knowledge management, knowledge transfer, knowledge exchange, dissemination, diffusion and other related terms.

There are some sectors where the process of knowledge mobilization is achieving greater success, and with greater speed, than other areas - for example, the oil industry (see Henrie \& Hedgepeth 2003) and oncology (Thompson et al. 2006) versus childcare (Lavis et al. 2003, p. 221) and environmental policy. While there is some research to draw upon at this moment, such as that found in the diffusion of innovation and the creation of technology centres, it is the opinion of this author that there is a correlation between existing infrastructure and incentives and the speed with which research moves into application.

\section{THE CREATION OF INCENTIVES}

In 1998, SSHRC launched the first round of a pilot program: Community-University Research Alliances (CURA). This program has had a significant effect on the administration and development of research support programs funded by the Canadian federal government and to a lesser extent on government agencies in other countries. It is also having an influence on the priorities of universities and scholarship in Canada.

A little background on the agency is important to understand the context of the emergence of the CURA program. The Social Sciences and Humanities Research Council of Canada was created in 1977 by an Act of Parliament to be an arm's-length federal agency that promotes and supports university-based research and training in the social sciences and humanities. It is governed by a twenty-two member advisory council and reports to Parliament through the Minister of Industry. The Grants and Scholarships budget for 20062007 was $\$ 306$ million (Canadian dollars). Allocation of these dollars is based on recommendations from volunteer experts that comprise the peer-review selection committees (SSHRC 2006).

The CURA program was created as a pilot program of grants to address issues arising from the effects of globalization and other forces on Canadian communities. SSHRC states that:

Many of these challenges are best addressed at the local and regional levels by the local and regional groups that best 
understand the needs of, and the factors affecting, particular communities. In addition, issues which cut across geographic boundaries are also best addressed by postsecondary institutions working closely with groups that represent particular "communities" of interest. In service of these goals, stronger alliances between community organizations and postsecondary institutions can be enormously effective and yield important benefits for them both. (SSHRC 2007)

As such, the program supports the working together of postsecondary institutions and community organizations as equal partners. The CURA program has four specific objectives: to promote the sharing of knowledge, resources and expertise between postsecondary institutions and organizations in the community; to enrich research, teaching methods and curricula in postsecondary institutions; to reinforce community decision-making and problemsolving capacity; and to enhance students' education and employability by means of diverse opportunities to build their knowledge, expertise and work skills through hands-on research and related experience (SSHRC 2007).

The original expectations for this program were modest. As the program officer in charge of the first competition cycle I was assured that we would receive no more than fifty or sixty letters of intent. These letters of intent were the first stage in a competition to receive one of eight full grants available. The first cycle produced 178 letters of intent. At the time, this was the largest number of applications to a strategic program ever received by SSHRC. The range of proposals submitted reflected both the diversity of Canadian society and the wide-ranging effects of globalization on communities. Senior administrators reacted to this demand by appropriately increasing the number of grants to be funded to twenty-two - a budget increase of almost threefold which was also unprecedented. What emerged from the adjudication process was not only a realization that there was a great demand for funding for community-university partnerships but also that a significant proportion of institutions and communities in Canada were already engaged in partnerships of one form or another. This form of self-organization is consistent with work identifying the paradoxes of self-organizing systems. Margaret Wheatley states that the viability and resiliency of the self-organizing 
system comes from its great capacity to adapt as needed to create structures that fit the moment (Wheatley 2006, p. 82).

It was apparent that communities, organizations and individuals across the country had been consistently interacting with colleges, universities and other post-secondary institutions in an effort to either find solutions to or better coping mechanisms for a range of problems affecting them. There was however a consistent lack of both financial resources and access to highly qualified individuals and data and information sources that could assist them to find the solutions they were looking for. In short, there was a lack of incentives to attract individuals to these local problems, as well as a lack of infrastructure linking them to each other in an efficient and potentially effective way.

The CURA program provided some resources and incentives which attracted a significant number of researchers and communitybased organizations. It also, given the size of the award (originally $\$ 200,000$ per year for three years, later increased to five years), provided incentives to administrators in postsecondary institutions to consider such partnerships to be of value despite the reality that these efforts were outside the normal academic frame of reference.

In 2004, I was invited by the government of Ile-de-France, which is the regional government that includes the city of Paris, to make a presentation on the SSHRC experience with the CURA program. The discussions which followed from this presentation led to the creation of a program called PICRI (Partenariats institutions / citoyens pour la recherche et l'innovation). The aim of this program is to stimulate partnerships between research institutions and not-for-profit organizations in order to facilitate the transfer of knowledge, resources and skills between these different bodies. The program also supports a range of actions aimed at stimulating the interests of the general public, and in particular of young people, in science and scientific research (European Commission 2007). While the PICRI program is based on the CURA program and provides similar incentives as well as some supports to further enhance societal benefit from collaborative research activities, it has accomplished something of considerable significance - it has linked researchers across disciplinary groupings to work collaboratively on complex issues that are affecting the ten-million-plus inhabitants of the region 
of Ile-de-France and is partially responsible for the emerging rise of interest in making Paris an eco-region.

A recent conversation with the Vice-President of Research for the region of Ile-de-France, Dr Marc Lipinski, during the 3rd Living Knowledge Conference, hosted at the Ecoles de Mines by La Fondation Sciences-Citoyennes, revealed both the ease with which the program was accepted at the political level as well as the growth of interest in engaging with the programming at a scientific level. Dr Lipinski stated that he expected to have to fight to see the program implemented. However, the reality was that his political colleagues considered the program to be a reasonably good idea but one that they had never considered. Having the opportunity brought to their attention, the value to the region was easily recognized and there was good support to implement and experiment. His advice to political representatives in other regions was simply to 'go for it'. At the scientific level, researchers and civil society organizations have come together on practical problems and have engaged in a co-creative process to identify the elements of a problem and implement solutions based on sound scientific research. An example includes the testing and rating of a range of electric wheelchairs for usability and durability in an urban Parisian context. Given the cost of these medical devices, as well as the critical need for them by their users, this was seen as a simple yet ultimately very useful project that would provide useable decision-making data to those funding the chairs as well as to those using them.

Also in 2004, the Ontario Ministry of Children and Youth Services provided the financial resources to create the Provincial Centre of Excellence for Child and Youth Mental Health at CHEO. The vision of the Centre is to have an integrated system that meets the holistic mental health needs of children, youth and their families, which is evidence-based and understood by the community at large (Manion 2004). Through a series of initiatives this Centre connects youth, children, families, caregivers, and parents to the granting agencies, community agencies, associations, academic health science centres, government and universities. They also link these actors to the health care system, the welfare system, the justice system and the education system.

While the Centre itself can be considered as infrastructure, it also plays the dual role of a facilitator that engages the diverse parts of a 
complex system that supports children and youth with mental health difficulties, and also acts as a catalyst that provides funding for community-campus research partnerships. The Centre states that it is committed to building capacity in the child and youth mental health sector, in part through its grants and awards programs. It acknowledges that this is accomplished by developing new knowledge, establishing new networks in partnerships, as well as by increasing the skills of those working in child and youth mental health through a variety of training initiatives (for more information on the Provincial Centre of Excellence for Child and Youth Mental Health at CHEO, including its grants and awards program). ${ }^{1}$

All research grants provided by the Centre must include community partners. They provide capacity building grants to community organizations and service providers to increase their skills in knowledge development and utilization. They also build capacity within the community by directly funding youth projects conceptualized, organized, implemented, and managed by youth. The Centre has brought the community directly into the policymaking arena by implementing a consumer's advisory group that makes recommendation to the Centre as well as to the Ministry.

\section{VALUE BEYOND THE FISCAL MARKETPLACE}

In each of the examples provided above, federal, provincial and regional governments have initiated spending and changes in the informational environment to entice research partnerships between parties that are not 'normally' in interaction with each other. However, in order to move from case studies or exceptional examples to normal streams of activity with consistent and sustained funding, it is important to have a structure for government (and institutional) policy, programming and decision-making to imagine and organize the possibilities within their particular contexts.

One important argument to present to these actors is that value creation is not limited to fiscal exchanges. There are multiple marketplaces, some of which have transactions measured in something other than monetary units. Initiatives that create value in the form of social relationships, safe communities, improved health, good housing, clean water, educated citizenry and a host of other social profits often require investments to support conceptualization

${ }^{1}$ See http://www.onthepoint.ca/index e.htm 
and development activities - in much the same way that small and medium-sized enterprises receive support and subsidies before they can be viable in the global marketplace. Without these supporting structures, substantial value goes undeveloped, underdeveloped or lost.

One way to imagine the role that various levels of government can play in supporting community-campus research is provided by the case of public health and public health law. In the taxonomy provided by Lawrence Gostin (2004), one sees that the State is imbued with powers to create the conditions for people to be healthy, as well as the power to constrain autonomy, privacy, liberty, proprietary or other legally protected interests of individuals for the promotion of community health. These include the power to tax and spend, alter the informational environment, alter the built environment, alter the socioeconomic environment, regulate directly, and indirectly, through the tort system and deregulate.

It can be argued that these State powers are not limited to public health. Applying the taxonomy of State powers to communitycampus research partnerships, several arguments may be put forth that call for greater support of community-campus research partnerships. In the case of most Federal governments, at least among the G25 countries, a certain proportion of tax dollars are spent supporting research - in Canada this is done in part via the granting agencies such as SSHRC, as well as the Natural Sciences and Engineering Research Council of Canada and the Canadian Institutes of Health Research. While the mandates of these organizations have a general focus on supporting university-based research, the Canadian Institutes of Health Research has a specific mandate with regard to knowledge transfer (for more information on its Knowledge Transfer Strategy for 2004-2009, 'Innovation in Action'. . There is very little inhibiting any level of government from directing taxes to support community-campus research partnerships other than political will, competition for research dollars from more established institutions, practices, disciplines or perspectives and inadequately demonstrated effectiveness of the methods dominant in collaborative research.

It is part of the political role of those engaged in collaborative research to build arguments which demonstrate the value of their work - value that otherwise would go unrealized. However, while

${ }^{2}$ See http:// www.cihr-irsc.gc.ca/e/26574.html 
this evaluation process is emerging, it needs to be made perfectly clear that it was an evaluation process, conducted by the President of SSHRC, Dr Marc Renaud, and the Vice-president of Knowledge Mobilization, Ms Pamela Wiggin, which ultimately led to the transformation of the CURA program from a pilot to an ongoing strategic program.

It is unlikely that there is anything in the legislative frameworks of any government that inhibits it from investing in and supporting programs and structures to facilitate community-campus research. As the interview with Dr Marc Lipinski in Paris indicated, most of his political colleagues have just not considered the idea and when presented with it, they considered it a worthy initiative to undertake.

The role of government to alter the information environment is not limited to restrictions but also to access: physical access and conceptual access - in this case to the results of publicly funded research. I remain surprised that there is not greater public demand for access to the results of work funded with public dollars. It is clear to me that if public dollars are used to support the research process, whether paying for the overhead in institutions, for the salaries to train highly qualified personnel, or for storing electronic and paper versions of various interpretations and analyses, then the same public should have access to the results of the research process, in a format that they can use and in a timely manner. The funding of communitycampus research in many ways alters the information environment. The co-construction of research questions, the collaborative analysis of results and the dynamic tension of determining how best to apply these results to the contexts in which people live produces value that otherwise remains as potential only on library shelves and in classroom desks.

Government has a role to play in altering the built environment that supports the research process. There are examples emerging in many places that show how to make university and college campuses more accessible to members of community-based organizations, citizen associations, community advocates and other organizations and individuals involved in the complex process of improving the social, environmental, economic and aesthetic conditions of their communities. Some of these examples include the science shops in Europe, the creation of specific offices within universities which act as intermediaries, such as the Office for Community-based Research 
at the University of Victoria, or a whole range of centres and institutes who include the public as a stakeholder rather than an audience member. While many of these initiatives have been led by individual activists or concerned academics, government has a role to play in supporting these initiatives, both in sharing success stories and in providing resources to restructure their public institutions to make them more accommodating, more welcoming and more useful to the concerns of the communities in which they find themselves. It is my opinion that one of the failures of the CURA program has been the lack of a systematic process to bring research projects and groups together to share methods, techniques, tools, data and concepts in a systematic manner. While some of this has happened in an ad hoc manner through the Community-University Expo conferences in Saskatoon, Winnipeg and in Victoria in 2008, there is a clear role for a national body to assist in the coordination and sharing of resources, data and opportunity.

While political philosophies between governments may differ with regard to how they alter the socioeconomic environments under their jurisdiction, there is significant research to show that disparities within populations are in fact detrimental to all within that population (Kawachi 1999). It is perhaps within the context of activities that reduce disparities within populations that government support for community-campus research may show the greatest results. While it has been demonstrated that education is one of the shortest routes out of poverty (Morrison 2002), an education that includes active involvement with community organizations has been shown to produce citizens that are more engaged in their communities and for longer periods of time (Lasker \& Weiss 2003). Government programs which support community-campus research may result in the triple positive outputs of providing an education, training a more engaged citizenry in the use of research methods and interpretation of research results, and producing data, information and mechanisms to reduce disparities and create a more equal socioeconomic environment for its citizenry. While I am not aware of any longitudinal research at this time this may be an area for further work.

Given that direct regulation, indirect regulation and deregulation are areas that are outside my experience or expertise, I leave the creation of arguments that look at these roles of government to others. However, it is clear to me that without some form of clear, 
concrete directive, which supports clear, concrete incentives and infrastructure that supports community-campus partnerships and collaborative research, it will be left to those activists, advocates and concerned academics currently involved in pushing for such to continue their quest - underwriting the costs of doing so out of their own pocket, energy and personal visions.

\section{MOVING FORWARD}

The late 1990s and the better part of this decade has seen substantial and significant increases in support for collaborative work. I've mentioned a few examples; however, I suggest that such initiatives exist, often in the shadows or in between other programs. It is important that the benefits and the value that is derived from engaging in collaborative work be made explicit, with a transparency of conversation about methods, limitations, opportunities and vision that reflects the best of the scientific methodology, while avoiding the worst of empire building, of ego inflation and of the creation of hierarchies that inhibit our collective abilities to produce solutions to our problems, or at the very least, better methods of coping with the problems that challenge us.

Government has been involved in the construction of the modern research enterprise from its very beginning and as such should be involved in the continued construction of the new forms of research. Governments have been involved in the creation of land grant universities, in the facilitation of research projects to change the socioeconomic conditions during the Great Depression, and in accommodating the great demographic shift that occurred due to the baby-boom. As noted above, SSHRC launched the CURA program in part as a reaction to globalization but also in recognition of the power of including all stakeholders in a context of the discovery and implementation of potential solutions to the challenges they face.

The only way to move forward is with a deliberate, systematic and transparent conversation about how best to support Mode Two research. Gibbons did not state that Mode Two would displace Mode One; rather Gibbons and colleagues assured us that these two processes are complementary rather than in competition with each other. There is a common statement about scientific inquiry that discovery is made by individuals standing on the shoulders of giants 
and that if it were not for the work of their predecessors, new knowledge would not be created.

Government is not the enemy of research and research is not the enemy of government. If one looks at the history of the research enterprise in all developed countries, one sees collaboration and a collective effort to engage in mutually beneficial activities. While there are moments of conflicting visions, lack of leadership and outright hostility, none of these should limit our imagination or our will to engage with each other in improving the conditions in which we live, both locally and globally, by using the best methods from science, from community and from the diversity of cultures that populate our increasingly connected world.

There is a clichéd statement that a population gets the government it deserves. I would argue that we do ourselves a great disservice when we choose not to involve the socially constructed frameworks of our governmental systems in the social construction of our communities. During a conference in Vancouver, in one of those conversations many of us have during coffee break, a native elder whose name I never got asked a question about research: 'What have we lost? Why are we RE-searching - should we not be searching?' I suggest that we need to search together to find better ways of asking questions, of finding answers and of implementing and utilizing these answers in ways that benefit more of us. It is at the core of community-campus research to find such ways and to use them. It is at the core of government to ensure that our populations are well cared for. It is apparent to me that there are more opportunities than obstacles - however, the words and the language that appeal to our decision makers have not yet been found. Perhaps some of the suggestions presented here will allow for that language to be developed and for the proper incentives and accompanying infrastructure to support collaborative research to continue to be built.

\section{REFERENCES}

European Commission 2007, 'Ile-de-France - Bringing science closer to society' (online), available: http:/ / ec.europa.eu/research/researchersineurope/news/article 2798 en.h $\underline{\mathrm{tm}}$, viewed 15 May 2007. 
Evans RG 1999, 'Purchasing population health: Paying for results', Journal of Health Politics, Policy, and Law, vol. 24, no. 5, pp. 1238-1244.

Gibbons, M, Limoges, C, Nowotny, H, Schwartzman, S, Scott, P \& Trow, M 1994, The new production of knowledge: The dynamics of science and research in contemporary societies, Sage, London.

Gostin, LO 2004, 'Health of the people: The highest law?', The Journal of Law, Medicine E Ethics, vol. 32, no. 3, pp. 509-515.

Gostin, LO 2005, 'The core values of public health law and ethics' in TM Bailey, T Caulfield \& NM Ries (eds), Public health law and policy in Canada, LexisNexis Canada, Markham, p. xi.

Henrie M \& Hedgepeth, O 2003, 'Size is important in knowledge management', Journal of Knowledge Management Practice, August.

Kawachi, I 1999, 'Social capital and community effects on population and individual health, Annals of the New York Academy of Science, vol. 896, pp. 120-130.

Lasker RD \& Weiss, ES 2003, 'Broadening participation in community problem-solving: A multidisciplinary model to support collaborative practice and research', Journal of Urban Health, vol. 80, no. 1, pp. 14-47.

Lavis, JN, Robertson, D, Woodside, JM, McLeod CB \& Abelson, J 2003, 'How can research organizations more effectively transfer research knowledge to decision makers', The Millbank Quarterley, vol. 81, no. 2, pp. 221-248.

Manion, I 2004, 'Best practices - building on the strengths: Children and youth with special needs', paper presented at the Ontario Children and Youth Summit, Toronto, 25 November 2004.

Marmot, M 2005, 'Social determinants of health inequalities', The Lancet, vol. 365, no. 9464, pp. 1099-1104.

Morrison, C 2002, Health, education and poverty reduction, OECD

Development Center, Paris.

Social Sciences and Humanities Research Council of Canada 2006, 'About SSHRC' (online), available: http:/ / www.sshrc.ca/web/about/about e.asp, viewed 16 April 2007. 
Social Sciences and Humanities Research Council of Canada 2007, 'Applying for funding: Community-University research alliances' (online), available: http://www.sshrc.ca/web/apply/program descriptions/cura e.asp, viewed 16 April 2007.

Thompson, GN, Estabrooks CA \& Degner, LF 2006, 'Clarifying the concepts in knowledge transfer: A literature review', Journal of Advanced Nursing, vol. 53, no. 6, pp. 691-701.

Wheatley, M 2006, Leadership and the new science: Discovering order in a chaotic world, Berrett-Koehler Publishers, San Francisco. 